\title{
MASSIVE LEFT VENTRICULAR PSEUDOANEURYSM
}

\author{
MENACHEM M. WEINER, MD AND RONALD A. KAHN, MD \\ DEPARTMENT OF ANESTHESIOLOGY, MOUNT SINAI SCHOOL OF MEDICINE, NEW YORK, NY, USA
}

KEY WORDS: Pseudoaneurysm · Transesophageal echocardiography.

A 50-year-old woman presented to the operating room for repair of a left ventricular pseudoaneurysm. She had a history of cardiac sarcoidosis which had manifested as dilated cardiomyopathy and recurrent ventricular tachycardia, which was treated with an endocardial/epicardial ablation six months ago. Transesophageal echocardiography at the transgastric basal short axis view demonstrated a $4 \mathrm{~cm}$ rupture of the basal inferolateral wall of the left ventricle close to the base of the posterior mitral valve annulus giving rise to a large $(9.5 \times 7 \mathrm{~cm})$ pseudoaneurysm (Fig. 1). Three dimensional reconstruction (Fig. 2) as seen from within the pseudoaneurysm looking into the left ventricle shows the extent of the rupture. The mitral valve apparatus can be seen through the defect. The patient underwent a patch closure of the defect.

The fundamental features that differentiate true aneurysms from false aneurysms are the presence of a continuous surrounding myocardial wall found in true aneurysms and the

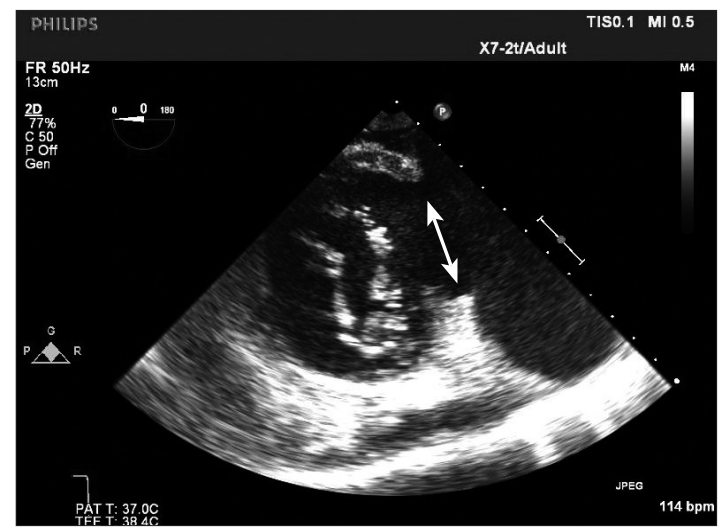

Fig. 1. Transesophageal echocardiography. The transgastric basal short axis view demonstrated a $4 \mathrm{~cm}$ rupture of the basal inferolateral wall of the left ventricle close to the base of the posterior mitral valve annulus giving rise to a large pseudoaneurysm. The neck of the pseudoaneurysm is indicated by the double-headed arrow. presence of a pericardial wall usually with mural thrombus found in false aneurysms. ${ }^{1)}$ Due to its lack of structural myocardial support, a left ventricular pseudoaneurysm carries a significant risk of expansion and fatal rupture and therefore requires an urgent surgical intervention. ${ }^{2)}$

- Acknowledgements

Support was provided solely from institutional and/or departmental sources.

\section{REFERENCES}

1. Brown SL, Gropler RJ, Harris KM. Distinguishing left ventricular aneurysm from pseudoaneurysm. A review of the literature. Chest 1997;111: 1403-9.

2. Atik FA, Navia JL, Vega PR, Gonzalez-Stawinski GV, Alster JM, Gillinov AM, Svensson LG, Pettersson BG, Lytle BW, Blackstone EH. Surgical treatment of postinfarction left ventricular pseudoaneurysm. Ann Thorac Surg 2007;83:526-31.

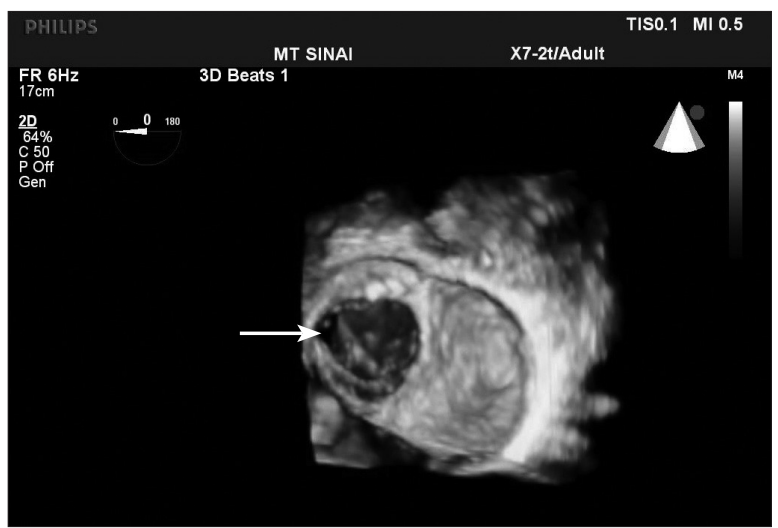

Fig. 2. Transesophageal echocardiography. Three dimensional reconstruction as seen from within the pseudoaneurysm looking into the left ventricle shows the extent of the rupture (see arrow). The mitral valve apparatus can be seen through the defect.

- Received: December 29, 2011 •Revised: January 22, 2012 •Accepted: February 16, 2012

- Address for Correspondence: Menachem M. Weiner, Department of Anesthesiology, The Mount Sinai Medical Center, 1 Gustave L. Levy Place, Box 1010,

New York, NY 10029-6574, USA Tel: +1-212-241-7467, Fax: +1-212-876-3906, E-mail: menachem.weiner@mountsinai.org

- This is an Open Access article distributed under the terms of the Creative Commons Attribution Non-Commercial License (http://creativecommons.org/licenses/by-nc/3.0)

which permits unrestricted non-commercial use, distribution, and reproduction in any medium, provided the original work is properly cited. 